\title{
Factors Influencing the Quality of Life in Patients with Chronic Kidney Failure Subject To Hemodialysis
}

\author{
José Luis Gamarra Insfrán " *1; Renato Soares Sanches Dias ${ }^{2}$; Cristina José Fernandes Sanches ${ }^{2}$ \\ ${ }^{1}$ Coordinator of the Research Department- Tres Fronteras International University - UNINTER - \\ Pedro Juan Caballero-Paraguay \\ ${ }^{2}$ University Student- Tres Fronteras International University -UNINTER- Pedro Juan Caballero - Paraguay \\ *Corresponding author: José Luis Gamarra Insfrán; raphael_fn@ hotmail.com
}

Received 10 January 2021;

Accepted 08 February 2021;

Published 24 February 2021

\begin{abstract}
Introduction: The patient with terminal chronic renal insufficiency in treatment with Dialysis, usually undergoes psychological and social changes, in his lifestyle and also in his spiritual life, which not only affect him, but the whole family of the. For this reason, it is essential to study the quality of life of this type of patient, since it allows us to analyze to what extent a patient's life is affected by the different interventions they require and by the damage caused by the disease and treatment. Objective: To describe the factors that influence the quality of life of patients with chronic renal failure undergoing hemodialysis in nephrology services. Materials and methods: A descriptive, retrospective and cross-sectional study was undertaken. $\underline{\text { Results: }}$ The research allowed determining that in the group of patients under study predominates: the older adult age range, married, presence of family support network, with complete basic education, of urban origin, with more than two pathologies associated with patient and in treatment for a period greater than one year. According to the Areas of the SF-36 health questionnaire, the Functional State Area is perceived as from Fair to Poor (90\%); the Welfare Area as Good (70\%), the General Health Perception as Good to Fair (92\%) and the Health Change over time as Good to Fair (55\%). Conclusion: In general, it was concluded that the perception of quality of life is Good. The factors considered to have an influence on this perception are: education, presence of a support network, marital status, origin, associated chronic pathologies and time on hemodialysis.
\end{abstract}

Keywords: Chronic renal failure, Hemodialysis, Quality of life.

\section{Introduction}

Chronic kidney disease (CKD) is a progressive, non-communicable disease closely linked to other diseases, such as cardiovascular disease (CVD) and diabetes mellitus (DM). Despite its preventable nature, its incidence is increasing throughout the world, mainly in times of globalization, in which new risk factors derived from production and consumption have been introduced, risks that have added to poverty and inequity social and health ${ }^{[1]}$. Worldwide, according to the International Society of Nephrology, there are 850 million people affected by this disease ${ }^{[2,3]}$. In the Latin American region, the prevalence is 447 patients per million inhabitants, and the incidence is 147 patients per million inhabitants. In Paraguay, only the prevalence of stage $5 \mathrm{CKD}$ is known, that is, patients on chronic dialysis, which is 165 / million inhabitants. But there is no data on the frequency of the other stages ${ }^{[5]}$.

With all the complications that this health problem brings, the destiny of these people if they are not treated, is sooner or later death. This destiny has changed dramatically with the advent of renal function replacement procedures through Dialysis and Kidney Transplantation ${ }^{[6]}$. The life expectancy of patients has improved remarkably with Dialysis and Kidney Transplant procedures. However, chronic kidney failure is a seriously lifethreatening condition with high morbidity and mortality ${ }^{[7]}$.

The development of dialysis techniques has produced a greater effect on the duration of survival of these patients. However, in systems that are increasingly affected by the economic aspect and the high cost of the treatments, on some occasions their justification is questioned and their true impact on another fundamental aspect such as the quality of the treatment is still pending. life of the patient with terminal $\mathrm{CKD}^{[8]}$.

This condition subjects the patient to multiple limitations, undoubtedly the ability to work is one of these, to which is added in our country the socioeconomic reality, which combines absence of social support, high levels of unemployment and decrease or lack of family income. For all this, a serious impact on the quality of life of patients is seen daily through aspects such as nutritional status, failures in self-esteem, depression, inability to acquire 
medications, access complementary studies, support their families and others ${ }^{[9]}$.

Although there is no doubt that hemodialysis is effective in prolonging the life of patients with nephropathy, there is considerable controversy regarding the quality of this survival, even more so when new dialysis modalities have focused on the potential benefits they offer to improve quality life span of patients ${ }^{[10]}$. The objective of this study was to describe the factors that influence the quality of life of patients with chronic renal failure undergoing hemodialysis in the nephrology services of a Public Hospital in Paraguay.

\section{Materials and Methods}

The present study is descriptive, retrospective and cross-sectional, carried out in the period from March 2018 to March 2019. The study population corresponds to patients with Chronic Renal Insufficiency in replacement treatment with hemodialysis, in the service Dialysis of a Public Hospital of Pedro Juan Caballero. The sample consisted of 40 patients, of which 3 patients did not agree to answer the survey. Therefore, the sample was made up of 37 patients, which constitutes $93 \%$ of the population. The inclusion criteria were, patients over 16 years of age with Chronic Renal Failure undergoing Hemodialysis and exclusion were patients with incomplete clinical records, with basic psychological or psychiatric alteration, with disease that made it impossible to communicate verbally and patients who did not agree to participate of the poll.

The information gathering method was direct, by means of a survey applied during a personal interview that was carried out with each patient in the dialysis service, while waiting or leaving their dialysis treatment schedule. The average time used to apply the questionnaire was approximately 20 minutes per patient. In the personal interview, an instrument consisting of three items was applied, which are: an instructive, the Personal History Questionnaire and the SF-36 Health Questionnaire. The instructions, which indicates how to complete the questionnaire, at the same time, includes the informed consent that guarantees the patient confidence, seriousness and confidentiality in the study. The Personal Background Questionnaire allowed characterizing the population. It consists of 10 closed questions: age, sex, education, forecast, occupation, marital status, origin, support network, associated chronic pathologies of the patient and time on hemodialysis.

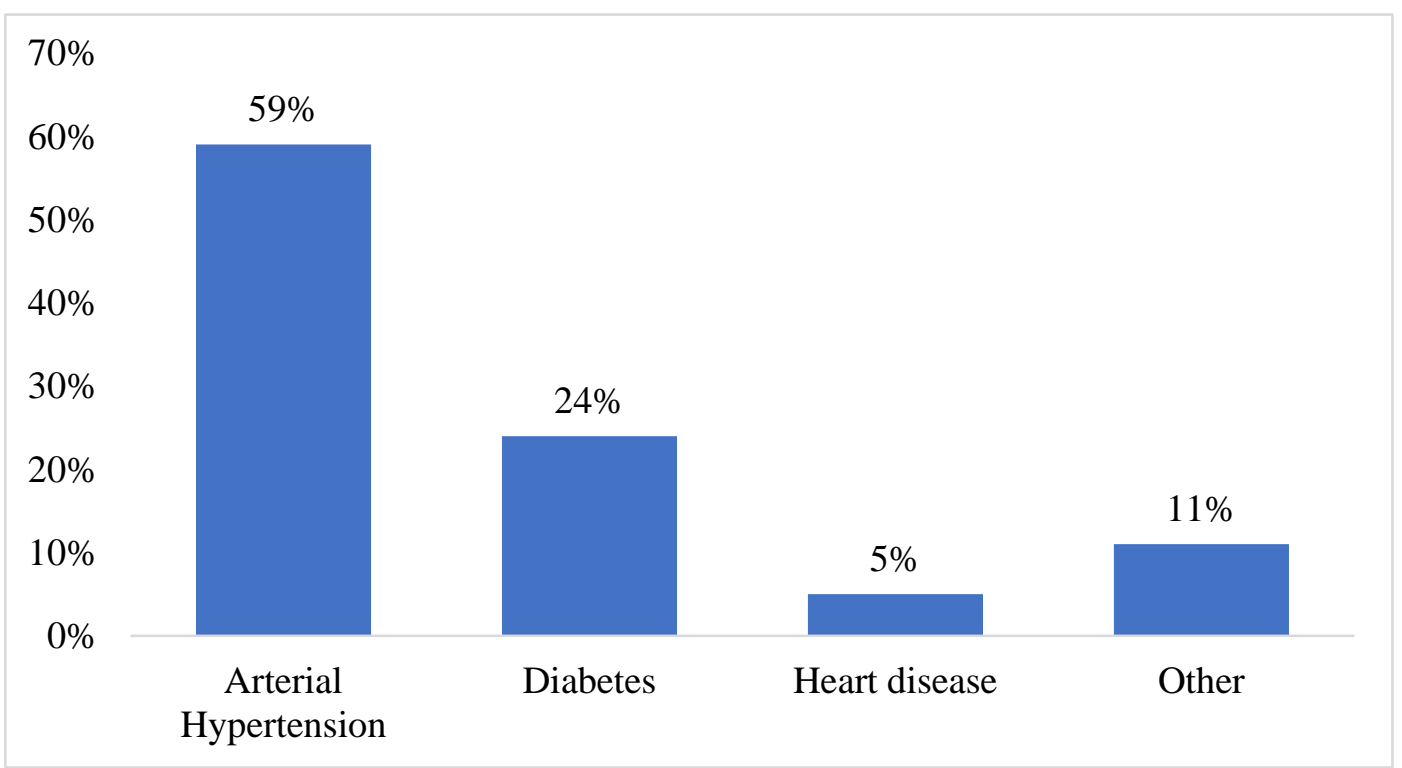


Regarding the associated chronic pathologies that the studied group presents, it can be seen that 59\% have Arterial Hypertension, 24\% Diabetes mellitus and $5 \%$ Heart Disease. $11 \%$ of the sample has other associated pathologies. It should be noted that most of the

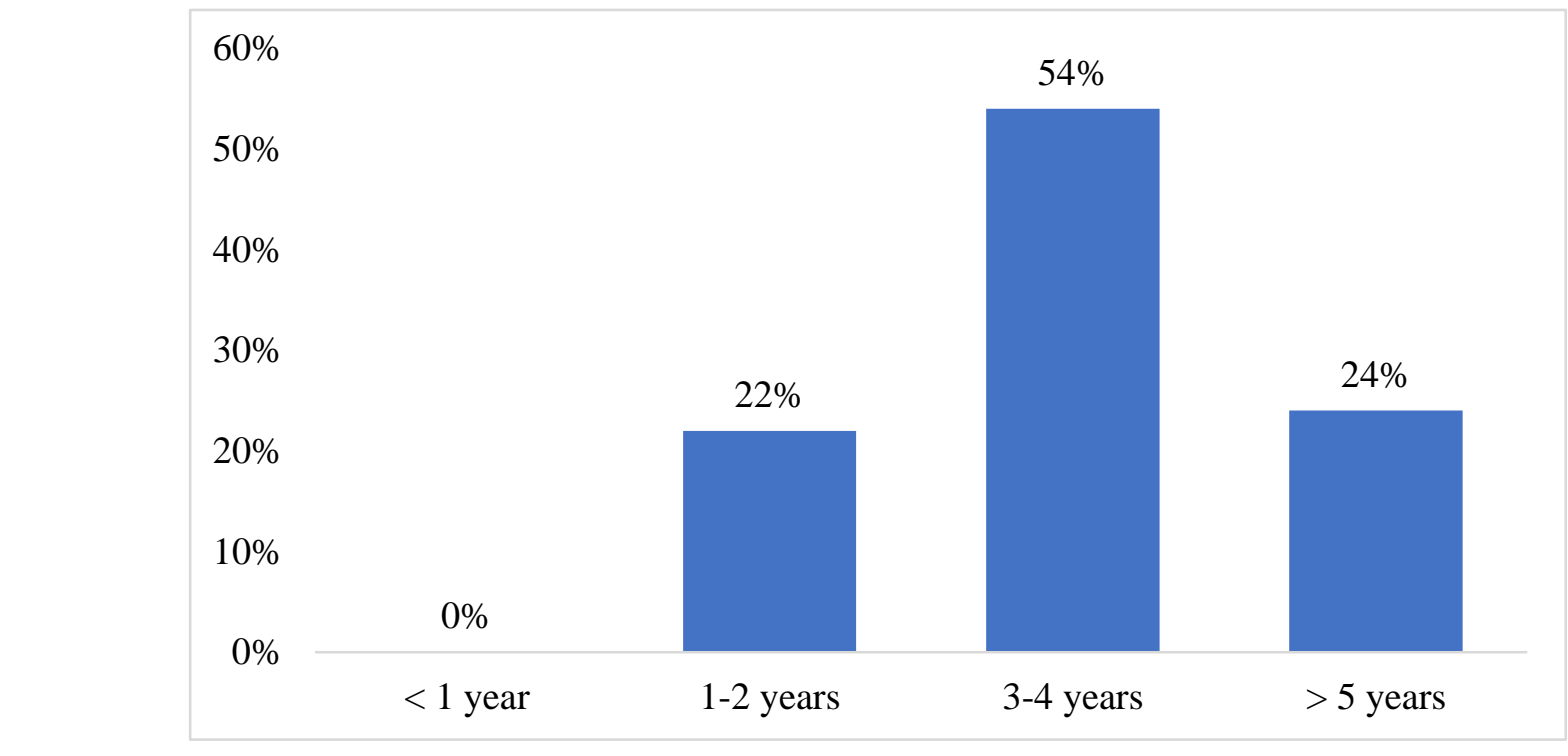

Graph 2: Percentage distribution of patients in replacement treatment with Hemodialysis according to time in Hemodialysis.

Regarding the time in hemodialysis of the study group, the graph shows that all the patients have been in treatment between 1 and more than 5 years, of which the majority (54\%) have been between patients surveyed present more than one of these pathologies at the same time, which leads to the deduction that to some extent their quality of life could be greatly affected.

Table 1: Percentage distribution of patients in substitution treatment with Hemodialysis according to perception of quality of life and time

\begin{tabular}{|l|l|l|l|l|l|l|l|l|}
\hline Perception of quality of life & \multicolumn{2}{|l|}{$\mathbf{1 - 2}$ years } & \multicolumn{2}{l|}{$\mathbf{3 - 4}$ years } & \multicolumn{2}{l|}{ Total } \\
\hline & $\mathbf{N}^{\circ}$ & $\mathbf{\%}$ & $\mathbf{N}^{\circ}$ & $\mathbf{\%}$ & $\mathbf{N}^{\circ}$ & $\mathbf{\%}$ & $\mathbf{N}^{\circ}$ & $\mathbf{\%}^{\circ}$ \\
\hline Excellent & 0 & $0 \%$ & 0 & $0 \%$ & 0 & $0 \%$ & 0 & $0 \%$ \\
\hline Very good & 4 & $50 \%$ & 8 & $40 \%$ & 3 & $33 \%$ & 15 & $41 \%$ \\
\hline Good & 2 & $25 \%$ & 5 & $25 \%$ & 3 & $33 \%$ & 10 & $27 \%$ \\
\hline Regular & 2 & $25 \%$ & 4 & $20 \%$ & 2 & $22 \%$ & 8 & $22 \%$ \\
\hline Bad & 0 & $0 \%$ & 3 & $15 \%$ & 1 & $11 \%$ & 4 & $11 \%$ \\
\hline TOTAL & $\mathbf{8}$ & $\mathbf{1 0 0 \%}$ & $\mathbf{2 0}$ & $\mathbf{1 0 0 \%}$ & $\mathbf{9}$ & $\mathbf{1 0 0 \%}$ & $\mathbf{3 7}$ & $\mathbf{1 0 0 \%}$ \\
\hline
\end{tabular}

In relation to the perception of the quality of life and the time on hemodialysis of the patients under study, it can be seen that in a general way the majority perceive their quality of life in the range of Very Good (41\%) Good (27\%), that is to say, that only sometimes have they felt in complete physical, mental, environmental and social well-being. It should be noted that patients who have been on hemodialysis between 1 and 2 years perceive their quality of life, in the range of Very Good (50\%) to
3 and 4 years and only $22 \%$ have been on treatment. 1 to 2 years of treatment. Importantly, all patients attend treatment three times a week.

Table 2: Numerical and percentage distribution of patients on replacement treatment with Hemodialysis according to functional status area.

\begin{tabular}{|c|c|c|c|c|c|c|c|c|c|c|c|c|}
\hline \multirow{3}{*}{$\begin{array}{l}\text { Functional State } \\
\text { Area }\end{array}$} & \multicolumn{12}{|c|}{ Perception of Functional State } \\
\hline & \multicolumn{2}{|c|}{ Excellent } & \multicolumn{2}{|c|}{ Very Good } & \multicolumn{2}{|c|}{ Good } & \multicolumn{2}{|c|}{ Regular } & \multicolumn{2}{|c|}{ Bad } & \multicolumn{2}{|c|}{ Total } \\
\hline & $\mathbf{N}^{\circ}$ & $\%$ & $\mathbf{N}^{\circ}$ & $\%$ & $\mathbf{N}^{\circ}$ & $\%$ & $\mathbf{N}^{\circ}$ & $\%$ & $\mathbf{N}^{\circ}$ & $\%$ & $\mathbf{N}^{\circ}$ & $\%$ \\
\hline Physical function & 1 & $3 \%$ & 7 & $19 \%$ & 10 & $27 \%$ & 12 & $32 \%$ & 8 & $22 \%$ & 37 & $100 \%$ \\
\hline Social function & $\mathbf{0}$ & 0\% & 5 & $14 \%$ & 8 & $22 \%$ & 13 & $35 \%$ & 11 & $30 \%$ & 37 & $100 \%$ \\
\hline Physical role & $\mathbf{1}$ & $3 \%$ & 2 & $5 \%$ & 3 & $8 \%$ & 18 & $49 \%$ & 14 & $38 \%$ & 37 & $100 \%$ \\
\hline Emotional role & 13 & $35 \%$ & 1 & $3 \%$ & 3 & $8 \%$ & 16 & $43 \%$ & 4 & $11 \%$ & 37 & $100 \%$ \\
\hline
\end{tabular}

In relation to the perception that patients have of the four dimensions measured by the Functional State Area, it can be said that: Regarding physical function, most patients rate it from Fair
Fair (50\%), while patients who have been on hemodialysis for more than 2 years years, most perceive their quality of life in the range of Good to Very Good. It could be deduced that the longer time on hemodialysis, the better is the perception of quality of life, this may be due to how well the patients feel with the treatment. Contrary to what one might think, as the years of treatment increase, one could deduce that hope in transplantation is being lost and therapy is becoming more and more exhausting. 
rate it as Regular (35\%) to Bad (30\%), that is, sometimes physical or emotional health problems interfere with the patient's social life.

Regarding the physical role, the majority of the patients rate it from Regular (49\%) to Bad (38\%), that is, most of the time physical health interferes with work and other daily activities, including performance less than desired. Regarding the Emotional
Role, most patients rate it as Fair (43\%) to Bad (11\%), that is, sometimes emotional problems interfere with work or other activities, including a reduction in the time dedicated to them. , lower performance and decreased dedication at work. In general, it can be seen that in the Functional State Area, most of the patients under study rated it from Fair to Poor.

Table 3: Numerical and percentage distribution of patients in substitution treatment with Hemodialysis according to the Welfare State Area

\begin{tabular}{|c|c|c|c|c|c|c|c|c|c|c|c|c|}
\hline \multirow{3}{*}{$\begin{array}{l}\text { Welfare State } \\
\text { Area }\end{array}$} & \multicolumn{12}{|c|}{ Perception of Functional State } \\
\hline & \multicolumn{2}{|c|}{ Excellent } & \multicolumn{2}{|c|}{ Very Good } & \multicolumn{2}{|c|}{ Good } & \multicolumn{2}{|c|}{ Regular } & \multicolumn{2}{|c|}{ Bad } & \multicolumn{2}{|c|}{ Total } \\
\hline & $\mathbf{N}^{\circ}$ & $\%$ & $\mathbf{N}^{\circ}$ & $\%$ & $\mathbf{N}^{\circ}$ & $\%$ & $\mathbf{N}^{\circ}$ & $\%$ & $\mathbf{N}^{\circ}$ & $\%$ & $\mathbf{N}^{\circ}$ & $\%$ \\
\hline Mental health & 1 & $3 \%$ & 13 & $35 \%$ & 16 & $43 \%$ & 4 & $11 \%$ & 4 & $11 \%$ & 37 & $100 \%$ \\
\hline Vitality & 0 & $0 \%$ & 5 & $14 \%$ & 21 & $57 \%$ & 7 & $19 \%$ & 4 & $11 \%$ & 37 & $100 \%$ \\
\hline Pain & 7 & $19 \%$ & 8 & $22 \%$ & 7 & $19 \%$ & 12 & $32 \%$ & 3 & $8 \%$ & 37 & $100 \%$ \\
\hline
\end{tabular}

In relation to the perception that patients have of the three dimensions measured by the Welfare State Area, it can be said that: In the Mental Health dimension, most patients rate from Very Good (35\%) to Good (43\%), that is to say, that sometimes, the patient has felt in complete psychological well-being. In relation to the Vitality dimension, it can be seen that most of the patients under study rate it as Good (57\%), that is to say, that sometimes the patient has felt energetic to carry out their activities. Regarding the Pain dimension, it can be seen that the majority of the patients in the study rate it from Good (19\%) to Excellent (19\%), that is, the patient has only sometimes presented pain, and therefore Therefore, this has only sometimes influenced his daily life. In general, it can be seen that in the Welfare State Area, most of the patients under study rate it from Good to Excellent.

Table 4: Numerical and percentage distribution of patients in replacement treatment with Hemodialysis according to general health evaluation area.

\begin{tabular}{|c|c|c|c|c|c|c|c|c|c|c|c|c|}
\hline \multirow{3}{*}{$\begin{array}{l}\text { General Evaluation Area } \\
\text { of the health }\end{array}$} & \multicolumn{12}{|c|}{ Perception of Functional State } \\
\hline & \multicolumn{2}{|c|}{ Excellent } & \multicolumn{2}{|c|}{ Very Good } & \multicolumn{2}{|c|}{ Good } & \multicolumn{2}{|c|}{ Regular } & \multicolumn{2}{|c|}{ Bad } & \multicolumn{2}{|c|}{ Total } \\
\hline & $\mathbf{N}^{\circ}$ & $\%$ & $\mathbf{N}^{\circ}$ & $\%$ & $\mathbf{N}^{\circ}$ & $\%$ & $\mathbf{N}^{\circ}$ & $\%$ & $\mathbf{N}^{\circ}$ & $\%$ & $\mathbf{N}^{\circ}$ & $\%$ \\
\hline General Health Perception & 2 & $5 \%$ & 9 & $24 \%$ & 13 & $35 \%$ & 12 & $32 \%$ & 3 & $8 \%$ & 37 & $100 \%$ \\
\hline Health change in the time & 9 & $24 \%$ & 14 & $38 \%$ & 8 & $22 \%$ & 1 & $3 \%$ & 5 & $14 \%$ & 37 & $100 \%$ \\
\hline Total & 11 & $30 \%$ & 23 & $62 \%$ & 21 & $57 \%$ & 13 & $35 \%$ & 8 & $22 \%$ & 74 & $200 \%$ \\
\hline
\end{tabular}

\section{Discussion}

From the results obtained from the studied population, in relation to age and sex, it can be mentioned that most of the patients $(67.5 \%)$ are in the age range of 50 to 70 years, which corresponds to the stage of Erikson's Mature and Elderly Adult, the predominant sex, is male (59\%), these data are consistent with those provided at the national level in Chile, in August 2005 by the Chilean Society of Nephrology, which as shown the majority are male $(53.4 \%)$

In relation to the associated chronic pathologies that the study population presents, it can be noted that $60 \%$ have Arterial Hypertension, 24\% have Diabetes Mellitus and 5\% have Heart Disease. It should be noted that most of the surveyed patients (60\%) have two more pathologies, apart from chronic kidney failure. Important fact, if it is considered that the more pathologies a person presents, the quality of life of that person could be more affected, by all that it means to live with a disease for life. We recognize that these factors are conditions that can lead to chronic kidney disease and coexist permanently in a patient ${ }^{[11]}$.

In relation to the perception of Quality of Life, the majority of patients (90\%) consider it from Fair to Very Good, that is, only sometimes the disease limits them in aspects such as diet, physical activity And social. This data coincides with that obtained by Elgueta et al .; who, in his study to measure the quality of life in people over 60 years of age in HDC, found that a significant percentage of all people on dialysis estimate their quality of life as high $^{[10]}$.
Regarding the time on hemodialysis of the study group, a majority of the patients have been in treatment between 3 and 5 years or more and $22 \%$ have been in treatment for 1 to 2 years. None of the patients have been on hemodialysis for less than a year. Data that coincide with the study carried out by Pérez, 2001 [10].

In relation to the three areas evaluated in the SF-36 health questionnaire; In the Functional Status area, most of the patients under study rate it from Fair to Poor. In this area four dimensions are measured; Regarding Physical Function, the majority (54\%) rate it from Bad to Fair, this must be because, as the majority (79\%) have been in treatment with HDC for more than 3 years, patients are getting used to living with limitations. $65 \%$ classified the Social Function from Regular to Poor, this may be due to the fact that the time that patients must dedicate for therapy is enough, therefore, it reduces their time to carry out social activities, on the other hand the limitations of the illness also alienates him from his circle of friends.

In the Physical Role dimension, $87 \%$ of the patients rate it from Fair to Poor, in this dimension it agrees with the study carried out by Perez (2001); says that "although this result could be considered to be contradictory with the one obtained in the physical dimension, the explanation may be that if the characteristics of the population under study are associated, they are people who, given their education, the job option to they can access, it is related to a work activity of greater physical effort than intellectual effort and that on many occasions they must abandon their work due to limitations of the disease and the treatment ${ }^{,[12]}$. Patients in another 
study reported that changes related to eating habits did not affect their reduction in energy and vitality. This study demonstrates the perception that our patients had in relation to their availability of energy and vitality ${ }^{[13]}$.

In the Emotional Role dimension, $62 \%$ rate it as Regular and 35\% rate it as Excellent, this must be due to the fact that most of the patients surveyed have a support network, and therefore feel supported by family members and / or friends. On the other hand, "our society is characterized by having great sensitivity and solidarity with people who face problems derived from any pathology, this has the effect that family and friends take actions to support and help people, when they are ill" ${ }^{[12]}$. In the Wellness area, the majority rate it as Good.

It should be noted that $70 \%$ rate this area in the range of Good to Excellent and only 30\% rate it as Bad. In this area, three dimensions are measured: regarding the Mental Health dimension, $78 \%$ of the patients rate it from Very Good to Good. This result is contradictory, if it is related to the antecedents of the scientific literature where the psychological condition of this type of patients stands out "with frequent periods of depression, aggressiveness and negative attitudes in their family group or towards health personnel" ${ }^{[12]}$. In the Vitality dimension, $57 \%$ rate it as Good, this score could be due to the fact that the therapy restores strength to each patient, they leave renewed after each hemodialysis session.

In the Pain dimension, $60 \%$ of the patients rate it from Good to Excellent, this coincides with the study by Perez (2001), it can be explained because, "the stabilization of patients on hemodialysis treatment, with some frequency, has as an effect, a regression of the indicators of the musculoskeletal system and therefore, a decrease in pain "[12]. Two other studies show us that patients with Chronic Renal Insufficiency highlight the experience with pain. Most of these data come from prevalent hemodialysis patients and show that more than $58 \%$ of patients with Chronic Renal Failure experience pain and $49 \%$ of patients classify their pain as moderate or severe. The prevalence of symptoms remains consistently high. Evaluations of peritoneal dialysis and patients with stage $5 \mathrm{CKD}$ treated conservatively without dialysis are scarce, although evidence suggests a similar prevalence and severity of pain for patients on chronic hemodialysis ${ }^{[14,15]}$.

Regarding the area of General Health Assessment, 92\% of the patients rate it in the range of Good to Fair, this could be due to the fact that most of the patients present more than one associated pathology. This does not agree with the study carried out by Marlis Perez in 2001, because the perception of the health of the population studied was rated from Good to Excellent, because 70\% did not present another associated pathology, totally contrary to what happens in this study.

In the Health Change over Time dimension, $62 \%$ rate it as Very Good to Excellent, that is, the majority of the group studied refers to being better than a year ago. This may be due to the fact that all patients have been in treatment for more than 1 year, therefore, the symptoms of the complications of Uremic Syndrome, metabolic alterations and fluid overload have decreased, which makes them consider that their health is better than a year ago.

Regarding the perception of the quality of life and the time on hemodialysis of the patients under study, the majority have been in treatment between 1 and 4 years and at the same time, the majority of them $90 \%$ perceive their quality of life in the range of Very Good to Fair, that is, many times they have felt in complete physical, mental, environmental and social well-being. It should be noted that the majority of patients who have been on hemodialysis between 1 and 2 years perceive their quality of life, in the range of Good to Fair, while of patients who have been on hemodialysis for more than 2 years, the majority perceive their quality of life. Quality of life in the range of Good to Very Good. The researchers of a 2009 systematic review evaluated that patients with adulthood and, consequently, a longer exposure to dialysis did not worsen serum markers and did not find a worsening in the quality of life of these patients, which corroborates the findings. data that we present [16].

It could be deduced that the longer time on hemodialysis, the better the perception of quality of life; this may be due to how well patients are feeling with the treatment. Contrary to what one might think, as the years of treatment increase, one could deduce that hope in transplantation is being lost and therapy is becoming more and more exhausting.

\section{Conclusion}

We conclude that despite the limitations caused by the disease itself, as well as the dialysis treatment, most of the patients surveyed perceive their quality of life as Good. Among the factors that positively influence this result, it is undoubtedly the support network, that is, having their family and friends in this process. This is considered the fundamental pillar of support for the patient with chronic disease, both to maintain self-care behaviors, a good mood, feel accompanied and at the same time maintain adherence to treatment. In this area, the profession of the doctor plays a fundamental role, because it can interact both with the patient and with her family members, making everyone participate in the treatment and thus make the entire disease process more bearable.

Knowing the perception of the quality of life, the staff in white can focus more on the real needs of the person and not see him only as a sick person, but as a "biopsychospiritual human being", that is, approach him in a more comprehensive way, it includes your values, beliefs and perceptions. This knowledge will allow to carry out interventions according to the characteristics and life situation that each person is going through in particular.

Finally, given the current trend, that is, the increase that has experienced, chronic diseases, especially CRI, within the population, it is important to emphasize the different levels of care. Especially what is at the primary level, as it is where this type of patients can be prevented and kept under control and educated about the complications that mismanagement of their pathologies can lead to.

\section{List of abbreviations}

Chronic kidney disease (CKD); cardiovascular disease (CVD); diabetes mellitus (DM)

\section{Conflicts of Interest}

The author(s) declare(s) that there is no conflict of interest regarding the publication of this paper.

\section{Authors' contributions}

The initial proposal was made by the JLGI and approved by all authors after submitting the research topic to a wide discussion and a better reformulation. RSSD conducted the literature review and collected all relevant data. CJFS and JLGI performed the data analysis. The Manuscript was written by JLGI, revised by all authors who agreed with its content and made the collective decision to submit it for consideration and possible publication 


\section{References}

[1] Lopera, MM. La enfermedad renal crónica en Colombia: necesidades en salud y respuesta del Sistema General de Seguridad Social en Salud. Revista Gerencia y Políticas de Salud, 2016;15(30): 212-233.

[2] International Society of Nephrology. (2019). 2019 United Nations High Level Meeting on UHC: Moving Together to Build Kidney Health worldwide. Retrieved 20 July 2019, https://www.theisn.org/images/Advocacy_4_pager_2019 _Final_WEB_pagebypage.pdf).

[3] Terán de Baudoin M Á. Enfermedad Renal Crónica. Rev. Act. Clin. Med. Disponible en: http://www.revistasbolivianas.org.bo/scielo.php?script=s ci_arttext\&pid=S2304-37682011000800009\&lng=es

[4] Torres Zamudio C. Insuficiencia renal crónica. Rev Med Hered. 2003;14( 1 ): 1-4.

[5] Andreu Periz D, Hidalgo Blanco M Á, Moreno Arroyo M C. Diagnóstico y prevención de la Enfermedad Renal Crónica. Enferm Nefrol. 2013;16( 3 ): 193-195.

[6] Cisternas H, Jara A, Rosenberg H, Vacarrezza A, Valdés G, Valdivieso A, Vial S, 1990. Temas de Nefrología. S. Vial. ed. Santiago,Chile, SA. 353 p.

[7] Gámez Jiménez A M, Montell Hernández OA, Ruano Quintero V, Alfonso de León José A, Hay de la Puente Zoto Marlen. Enfermedad renal crónica en el adulto mayor. Rev. Med. Electrón. 2013; 35(4): 306-318.

[8] Bencomo Rodríguez O. Enfermedad Renal Crónica: prevenirla, mejor que tratarla. Revista Cubana de Medicina General Integral. 2015; 31(3):353-362

[9] Veronese FV, Gomes EC, Chanan J, Carraro MA, Camargo EG, Soares AA, Thomé FS, Silveiro SP. Performance of CKD-EPI equation to estimate glomerular filtration rate as compared to MDRD equation in South Brazilian individuals in each stage of renal function. 2014;52(12):1747-54

[10] Elgueta, H.; Mañalich; A. Saffie. 1994. "Hemodiálisis Crónica: Programa De Evaluación De Calidad De Vida En Pacientes Mayores De 60 Años". Revista Médica De Chile. 122: 679-685.

[11] Vanholder R, Annemans L, Brown E, et al. Reducing the costs of chronic kidney disease while delivering quality health care: a call to action. Nat Rev Nephrol. 2017;13(7):393-409. doi:10.1038/nrneph.2017.63

[12] Pérez, M. 2001. Medición De La Calidad De Vida Percibida En Pacientes Con Irct En Terapia De Hdc. Centro Médico Nefroval. Valdivia 2000. Tesis Para Optar Al Grado De Lic. En Enfermería. Valdivia, Uach, Facultad De Medicina.60 P.

[13] Burrowes JD, Larive B, Cockram DB, et al. Effects of dietary intake, appetite, and eating habits on dialysis and non-dialysis treatment days in hemodialysis patients: cross-sectional results from the HEMO study. Journal of Renal Nutrition : the Official Journal of the Council on Renal Nutrition of the National Kidney Foundation. 2003 13(3):191-198. DOI: 10.1016/s1051-2276(03)00069-4.

[14] Murphy EL, Murtagh FE, Carey I, Sheerin NS. Understanding symptoms in patients with advanced chronic kidney disease managed without dialysis: use of a short patient-completed assessment tool. Nephron Clin Pract. 2009;111(1):c74-c80. doi:10.1159/000183177

[15] Noble H, Meyer PJ, Bridge DJ, Johnson DB, Kelly DD: Exploring symptoms in patients managed without dialysis: a qualitative research study. J Ren Care. 2010; 36:9-15.

[16] Carson RC, Juszczak M, Davenport A, Burns A. Is Maximum Conservative Management an Equivalent Treatment Option to Dialysis for Elderly Patients with Significant Comorbid Disease? CJASN. 2009;4(10):1611-1619; Doi: 10.2215/CJN.00510109 